\title{
Characterization of polyparaphenylene (PPP)-based carbons
}

\author{
M. J. Matthews \\ Department of Physics, Massachusetts Institute of Technology, Cambridge, Massachusetts 02139 \\ M. S. Dresselhaus \\ Department of Electrical Engineering and Computer Science and Department of Physics, \\ Massachusetts Institute of Technology, Cambridge, Massachusetts 02139 \\ M. Endo, Y. Sasabe, T. Takahashi, and K. Takeuchi \\ Faculty of Engineering, Shinshu University, 500 Wakasato, Nagano 380, Japan
}

(Received 18 December 1995; accepted 5 September 1996)

Polyparaphenylene (PPP)-based carbons heat-treated at temperatures $\left(T_{\mathrm{HT}}\right)$ from $600{ }^{\circ} \mathrm{C}$ up to $3000{ }^{\circ} \mathrm{C}$ have been characterized both structurally and in terms of their physical properties. Special attention is given to PPP heat-treated at $700{ }^{\circ} \mathrm{C}$ (denoted by PPP-700), since samples heat-treated to this temperature were observed to have exceptionally high lithium affinities when electrochemically doped with Li. At low $T_{\mathrm{HT}}$ below $700{ }^{\circ} \mathrm{C}$, it is found that the local structure of PPP-based samples can be characterized mostly in terms of a disordered polymer. As a result of heat treatment to high temperature, PPP-based carbon shows graphitization behavior with regard to x-ray diffraction $d_{002}$ (graphite $c$-axis $d$-spacing) development and to the increase of the Raman $I_{G} / I_{D}$ intensity ratio (where $I_{G}$ and $I_{D}$ are the integrated intensities of the $1580 \mathrm{~cm}^{-1}$ and $1360 \mathrm{~cm}^{-1}$ Raman modes, respectively), as is found in so-called graphitizing carbons. However, development of the $c$-axis crystallite size $\left(L_{c}\right)$ is restricted to very small values, in the range of so-called nongraphitizing carbons, while the $a$-axis crystallite size $\left(L_{a}\right)$ attains values up to roughly $120 \AA$ for heat treatments near $3000{ }^{\circ} \mathrm{C}$. These structural properties of PPP-based carbons are consistent with the observed electrical characteristics and their dependence on $T_{\mathrm{HT}}$. Low temperature magnetic susceptibility measurements were analyzed, along with Raman spectra, allowing for the characterization of disorder in terms of localized spin states for several heat-treated PPP samples. By interpreting the results of these various characterization techniques, we are able to present an insightful perspective on the nature of PPP-based carbons and the role of PPP-700 as an effective lithium host material for secondary battery applications.

\section{INTRODUCTION}

To enhance the capabilities of many present lap-top computers and other electronic products, it would be highly beneficial to increase the power storage capacity of rechargeable batteries, such as so-called lithium ion batteries. Much effort has been expended and a large number of disordered and well-ordered graphite materials have been tested for use as carbon anodes in high capacity lithium ion batteries. ${ }^{1-6}$ Polyparaphenylene (PPP)-based carbons, heat-treated at temperatures as low as $700{ }^{\circ} \mathrm{C}$, have been shown to yield a superior negative electrode material, with energy storage capacities as high as $1170 \mathrm{~A}-\mathrm{h} / \mathrm{kg}$. This extremely high Li storage capacity in PPP-based, low heat-treatment temperature materials, which is about three times greater than that of wellordered, graphite-based, first stage intercalation compounds (e.g., $\mathrm{LiC}_{6}$ ), is believed to arise from the special structure of PPP-based carbon. ${ }^{7}$ Indeed, these low $T_{\mathrm{HT}}$ PPP-based carbons contrast most $\mathrm{Li}_{x} \mathrm{C}_{6}$ host materials not only in structure, but in chemical composition as well (atomic $\mathrm{H} / \mathrm{C} \sim 0.24$ for PPP-700).

To characterize PPP-based carbons, we have studied the structure and electrical transport properties of PPPbased carbons as a function of heat-treatment temperature, $T_{\mathrm{HT}}$, from $600{ }^{\circ} \mathrm{C}$ extending to $3000{ }^{\circ} \mathrm{C}$. The structural characterization measurements include $\mathrm{x}$-ray diffraction studies, yielding the $d_{002}$ distance and the $c$-axis crystallite size $L_{c}$, and Raman scattering which can be used to obtain information on the $L_{a}$ crystallite length and the degree of in-plane order for $T_{\mathrm{HT}}>$ $800{ }^{\circ} \mathrm{C}$. Raman spectroscopy was also used to study the interesting structural changes brought about by the thermal decomposition of PPP in the range $600{ }^{\circ} \mathrm{C}<T_{\mathrm{HT}}<$ $800{ }^{\circ} \mathrm{C}$. Magnetic susceptibility and resistivity measurements were performed in order to characterize the electronic states of localized and delocalized carriers as a function of measurement temperature for all heat-treated samples. TEM and SEM measurements were also carried 
out on samples heat-treated to $700{ }^{\circ} \mathrm{C}$ to determine other special features associated with this material, since PPP700 has been shown to be optimum for Li uptake.

\section{EXPERIMENTAL}

The PPP used in the present experiments has been synthesized by the Kovacic method (see Fig. 1) using a reaction vessel maintained at $30{ }^{\circ} \mathrm{C}$, yielding PPP in granular form. ${ }^{8}$ Samples of this material were subsequently heat-treated to various temperatures between 600 and $3000{ }^{\circ} \mathrm{C}$ in high purity argon gas, using a conventional resistance furnace for heat-treatment temperatures $<1000{ }^{\circ} \mathrm{C}$ and a graphite resistance furnace for $T_{\mathrm{HT}}>1000^{\circ} \mathrm{C}$. A residence time of $1 \mathrm{~h}$ was used for the heat treatment. Subsequent to preparation and heat treatment, the samples were characterized by $\mathrm{x}$-ray diffraction (XRD). In order to form a sample suitable for electrical measurements, the granular PPP material was pressed into appropriate shapes $(2 \mathrm{~mm} \times 2 \mathrm{~mm} \times$ $15 \mathrm{~mm}$ ), and these shaped samples were heat-treated in the same manner as the granular sample material. Electrical measurements were made on the shaped samples using four-point electrical resistance techniques to obtain values for the room temperature resistance and then for the more detailed temperature-dependent electrical resistivity for each of the heat-treated PPP bulk samples. The voltage between the middle two contacts was measured using a Keithley model 181 digital nanovoltmeter, while the current through the outer two leads was provided by a Keithley model 225 nanoampere current source. The temperature scans from about $25 \mathrm{~K}$ up to $300 \mathrm{~K}$ took place through natural warming of the sample in the $\mathrm{He}$ cryostat. The resistivity of each sample was calculated using the measured resistance and the measured crosssectional area and length. For PPP-based carbon material heat-treated at $T_{\mathrm{HT}} \sim 700{ }^{\circ} \mathrm{C}$ and $2900{ }^{\circ} \mathrm{C}$, additional characterization was carried out using high resolution SEM and TEM. The TEM studies were carried out on a JEOL $400 \mathrm{kV}$ TEM instrument. Raman scattering experiments were performed at ambient conditions using a back-scattering geometry with $4880 \AA$ as the laser excitation wavelength. Scattered light was resolved through a $300 \mu \mathrm{m}$ slit into a SPEX double monochromator and measured using a liquid nitrogen cooled CCD detector. Magnetic susceptibility measurements were made using a Quantum Design SQUID magnetometer over the temperature range $4-200 \mathrm{~K}$ in magnetic fields up to $5 \mathrm{kG}$.

\section{SAMPLE PREPARATION}

As a function of $T_{\mathrm{HT}}$, PPP changes more gradually to a graphitic material than is common for so-called graphitizing materials ${ }^{9}$ as is shown in Fig. 2, where the carbon yield for PPP vs $T_{\mathrm{HT}}$ is plotted. In this work, carbon yield is defined as the ratio of the weight of carbon produced through heat treatment to the weight of starting material (PPP). The results show a gradual decrease in the carbon yield with increasing $T_{\mathrm{HT}}$ as more hydrogen and hydrocarbon volatiles are vaporized from the sample over the range $600{ }^{\circ} \mathrm{C}<T_{\mathrm{HT}}<2400{ }^{\circ} \mathrm{C}$. The data show the superior carbon yield behavior of PPP in contrast to a furfurol alcohol-based carbon, a typical nongraphitizing (glassy) carbon which shows a very rapid decrease in carbon yield with increasing $T_{\mathrm{HT}}$ as well as a lower value of the carbon yield at stabilization. As $T_{\mathrm{HT}}$ increases above $2400{ }^{\circ} \mathrm{C}$, the carbon yield for PPP stabilizes at $\sim 70 \%$. For characterization purposes, PPP with a $T_{\mathrm{HT}}$ of $600{ }^{\circ} \mathrm{C}$ has a dark bronze color, which changes to black for $T_{\mathrm{HT}} \geqslant 700^{\circ} \mathrm{C}$. Figure 2 shows that PPP-based carbon can thus be characterized as one of the high yield carbons. ${ }^{10}$

\section{EXPERIMENTAL RESULTS}

\section{A. X-ray diffraction}

Figure 3 shows the (002) x-ray diffraction peaks for PPP-based samples heat-treated at various temperatures. A silicon powder sample is used as an internal standard for calibration of the interlayer separation $d_{002}$ and to determine the crystallite thickness $L_{c}$. The PPP-700 material shows a very broad (002) peak as seen in Fig. 3, indicating a highly disordered carbonaceous material, while PPP-2900 shows a sharp graphitic structure. Little change in the x-ray spectra is seen between the PPP700, PPP-800, and PPP-1000 samples. However, major changes in the peak resolution and linewidth are observed between the PPP-1000, PPP-1500, and PPP-2000 traces in Fig. 3. Finally, a sharp (002) feature appears for the PPP-2400 trace, and an even sharper (002) feature for the PPP-2900 trace. We note that no (112) diffraction peak, which would appear at $83.6^{\circ}$, was observed for PPP-2900, indicative of the turbostratic behavior of the material. For a given $T_{\mathrm{HT}}$, no clear difference in the $\mathrm{x}$-ray diffraction profile was observed between powder samples and bulk samples (pressed from powder) which were used for transport measurements.
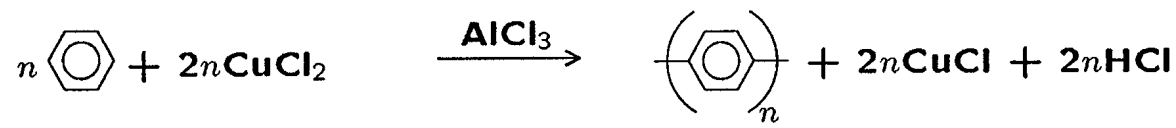

FIG. 1. Chemical reaction for the formation of PPP (polyparaphenylene) by the Kovacic method. 


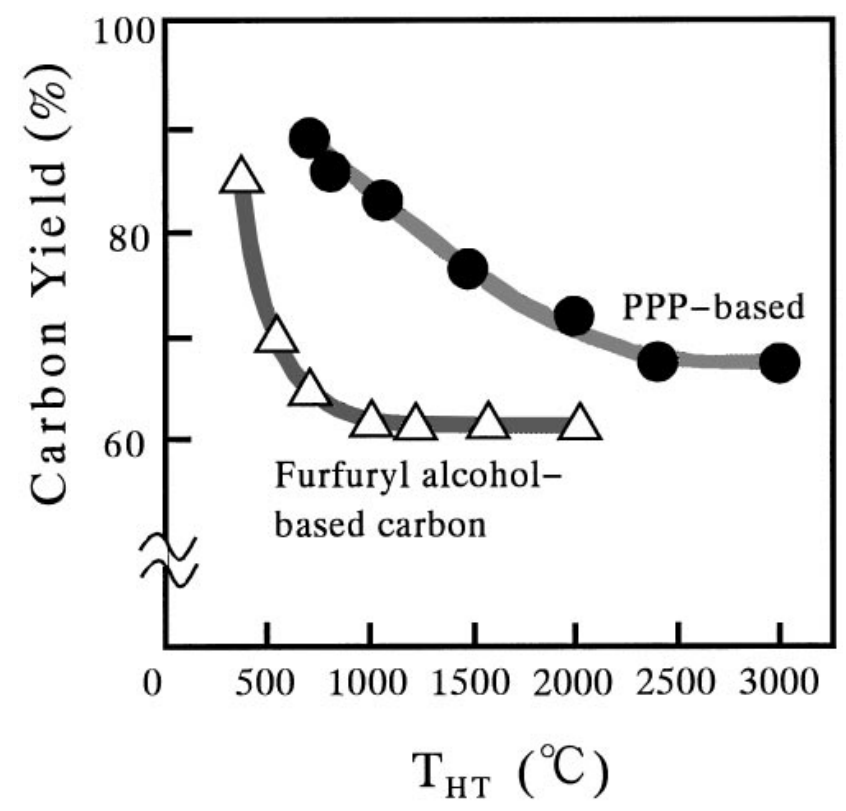

FIG. 2. Carbon yield of PPP-based carbon as a function of $T_{\mathrm{HT}}$ in an argon atmosphere. Included for comparison is the carbon yield of furfuryl alcohol-based carbon.

Figures 4(a) and 4(b), respectively, show the $T_{\mathrm{HT}}$ dependence of the interlayer separation distance $d_{002}$ and the apparent $c$-axis crystallite size $L_{c}$, as determined by XRD measurements, indicating graphitizing behavior of PPP at high heat-treatment temperatures. The $L_{c}$ in Fig. 4 were determined from the half-width of the $(002)$ diffraction line, taking into account Lorentz polarization and the atomic scattering factor, and using the $\operatorname{Si}(111)$ peak as an internal standard. In Fig. 4, a comparison is also made between the graphitization of PPP-based carbon and vapor-grown carbon fibers (VGCF's), which represent one of the typical graphitizing carbons. The interlayer spacing of PPP-700 is $3.77 \AA$, which is a rather large value even for a turbostratic carbon, but $d_{002}$ decreases progressively with increasing $T_{\mathrm{HT}}$, reaching a value of $3.37 \AA$ at $T_{\mathrm{HT}}=2900^{\circ} \mathrm{C}$, close to the graphite value of $3.35 \AA$ for $d_{002}$. It is clearly seen from the large change in $d_{002}$ as a function of $T_{\mathrm{HT}}$ that PPPbased carbons are transformed from a highly disordered material at $T_{\mathrm{HT}} \sim 700{ }^{\circ} \mathrm{C}$ to a relatively well-graphitized carbon form for PPP-2900. On the other hand, the crystallite thickness $L_{c}$ in Fig. 4(b) does not show such a large increase with $T_{\mathrm{HT}}$ as is normally found in graphitizing carbons. Rather, Fig. 4(b) shows increases in $L_{c}$ from $\sim 10 \AA$ at $T_{\mathrm{HT}} \sim 700^{\circ} \mathrm{C}$ to $\sim 90 \AA$ at $T_{\mathrm{HT}} \sim$ $2900{ }^{\circ} \mathrm{C}$. Figure 4 further shows that $L_{c}$ for vapor-grown carbon fibers increases from $\sim 50 \AA$ for $T_{\mathrm{HT}} \sim 1050{ }^{\circ} \mathrm{C}$ (as-prepared sample) to about $300 \AA$ for $T_{\mathrm{HT}} \sim 1900^{\circ} \mathrm{C}$, and to over $1000 \AA$ for $T_{\mathrm{HT}} \sim 3000^{\circ} \mathrm{C}$ (not shown). The properties of PPP-based carbon samples are summarized in Table I with the degree of graphitization $G$ for $T_{\mathrm{HT}} \geqslant$

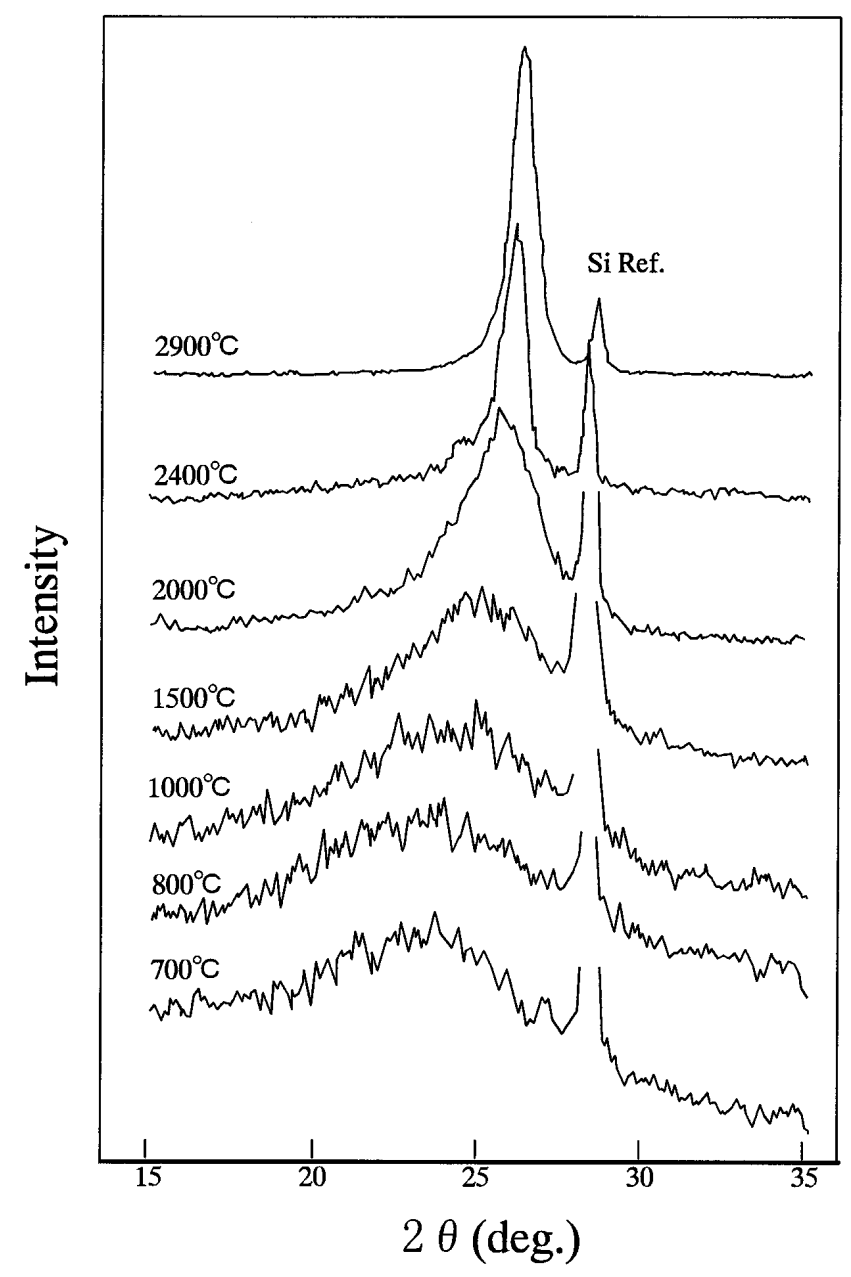

FIG. 3. (002) X-ray diffraction profiles for PPP-based carbons heat-treated at $700-2900{ }^{\circ} \mathrm{C}$. The $\mathrm{Si}(111)$ peak is used as an internal standard.

$2000{ }^{\circ} \mathrm{C}$ given by

$$
\mathcal{G}=\frac{3.44-d_{002}}{3.44-3.354}
$$

where $G=0$ corresponds to the turbostratic limit $\left(d_{002}=3.44 \AA\right)$ and $G=1$ corresponds to a completely graphitized material $\left(d_{002}=3.354 \AA\right)$. Thus, in PPPbased carbon, graphitization starts at a relatively high temperature, such as $T_{\mathrm{HT}}=2000{ }^{\circ} \mathrm{C}$, which is about $600{ }^{\circ} \mathrm{C}$ higher than that for typical graphitizing carbons such as VGCF.

From a structural standpoint, the PPP-based carbon shows graphitizing behavior in some ways, but not in others. When the PPP-based carbon is characterized by the interlayer separation, it appears to be a graphitizing carbon, but with a crystallite thickness $L_{c}$ that is restricted to small values characteristic of nongraphitizing carbons. The restrictions to the growth of $L_{c}$ may arise from the molecular structure of the precursor PPP, which has a chain molecular configuration. As the crystallite 


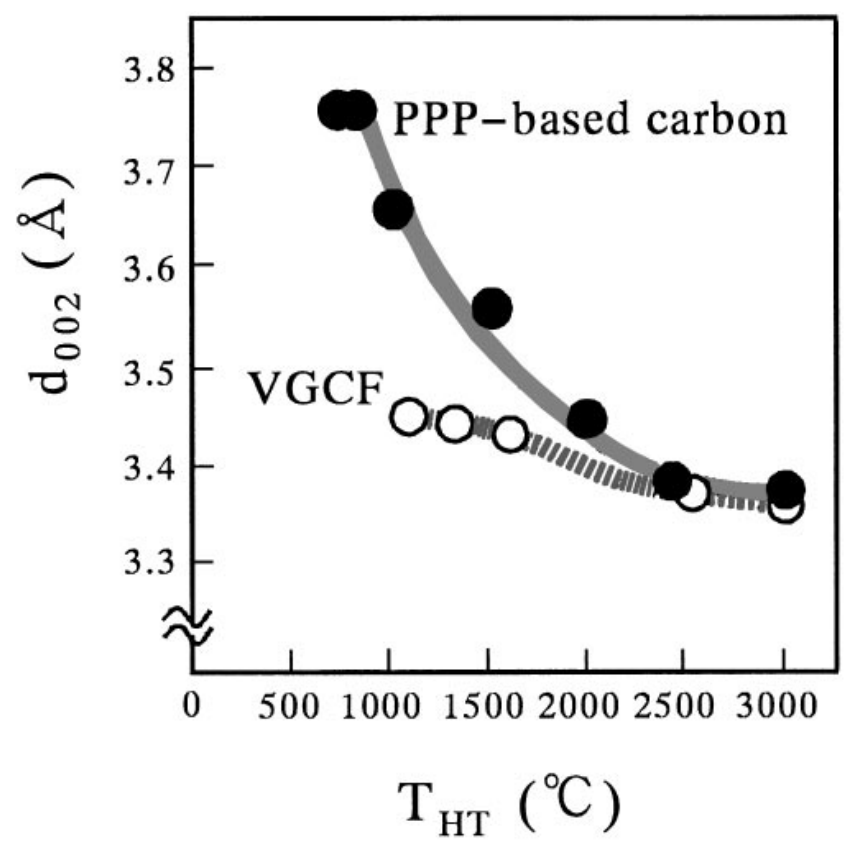

(a)

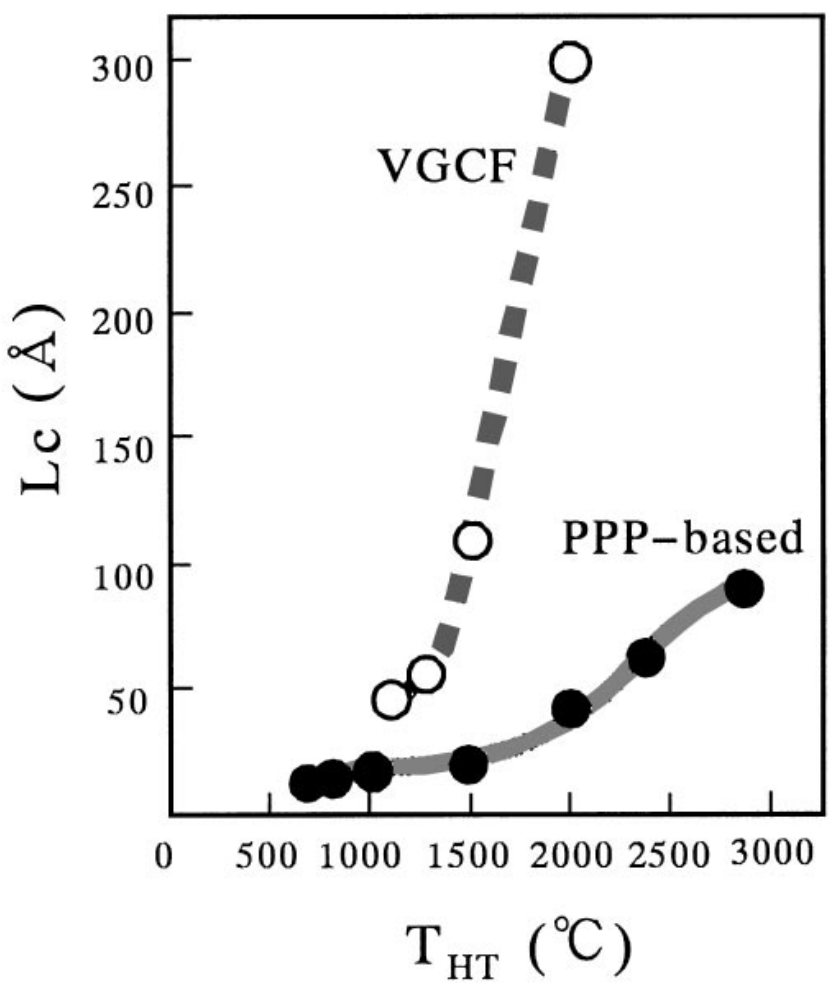

(b)

FIG. 4. The interlayer separation distance $d_{002}$ (a) and crystallite thickness $L_{c}$ (b) versus heat-treatment temperature $T_{\mathrm{HT}}$. The data for PPP are compared with corresponding data for vapor-grown carbon fibers (VGCF's).
TABLE I. Summary of samples studied.

\begin{tabular}{lccccc}
\hline \hline \multicolumn{1}{c}{ Sample } & $L_{c}(\AA)$ & $d_{002}(\AA)$ & $G$ & $I_{D} / I_{G}{ }^{a}$ & $L_{a}(\AA)$ \\
\hline PPP-700 & 11 & 3.77 & $\ldots$ & $\ldots$ & $\ldots$ \\
PPP-800 & 15 & 3.77 & $\ldots$ & 1.7 & 26 \\
PPP-1000 & 20 & 3.65 & $\ldots$ & 1.7 & 26 \\
PPP-1500 & 23 & 3.56 & $\ldots$ & 1.0 & 44 \\
PPP-2000 & 42 & 3.44 & 0 & 0.65 & 68 \\
PPP-2400 & 65 & 3.38 & 0.70 & 0.48 & 92 \\
PPP-2900 & 90 & 3.37 & 0.81 & 0.36 & 122 \\
VGCF-1050 & 46 & 3.44 & 0 & 0.90 & 49 \\
VGCF-1900 & 300 & 3.36 & 0.93 & 0.35 & 126 \\
\hline \hline
\end{tabular}

${ }^{a}$ The ratio of Raman intensities is a measure of the degree of graphitization.

develops, the chains stack several layers deep, but remain entangled with each other. Thus the interlayer spacing of PPP develops as a graphitizing carbon, but the increase in $L_{c}$ develops slowly, in a manner of nongraphitizing carbons.

\section{B. SEM and TEM}

Figure 5 shows a high resolution field emission FESEM micrograph of the original PPP sample and of the heat-treated samples PPP-700, PPP-2400, and PPP2900 obtained at low acceleration voltages $(\sim 5 \mathrm{keV})$. To avoid charging effects, the original PPP sample was coated with gold in taking the FE-SEM image. The heattreated granular samples were directly mounted on the SEM observation stage without further pulverization. The SEM micrographs indicate a characteristic porous and granular microstructure for each sample, different from that of common graphitizing carbons which show a platelet-like appearance with a well-developed stacked structure. ${ }^{11}$ It would be worthwhile to identify the high density of pores in the PPP-700 sample which can act as a pathway for the electrolyte motion in secondary battery applications.

We now compare the texture of the PPP-700, PPP2400, and PPP-2700 samples. The PPP-700 sample shows a porous structure arising from outgasing and carbonization. Upon heating the sample to $2400^{\circ} \mathrm{C}$, the material initially becomes more bulky as a result of increased densification, but upon further heat treatment to $2900{ }^{\circ} \mathrm{C}$, the sample becomes more porous again as a result of graphitization, with a final porosity similar to the porosity of the PPP-700 sample. It is also interesting to note in the SEM image of Fig. 5(b) that the PPP-700 samples typically consist of two types of pores: larger pores with a width of $\sim 1 \mu \mathrm{m}$ size (arrow L) among the granular areas, and smaller pores with widths in the range between 50 and several hundred $\mathrm{nm}$ (arrow S), presumably formed by a puffing mechanism. From these small pores, pyrolytically decomposed gases from PPP are ejected. 


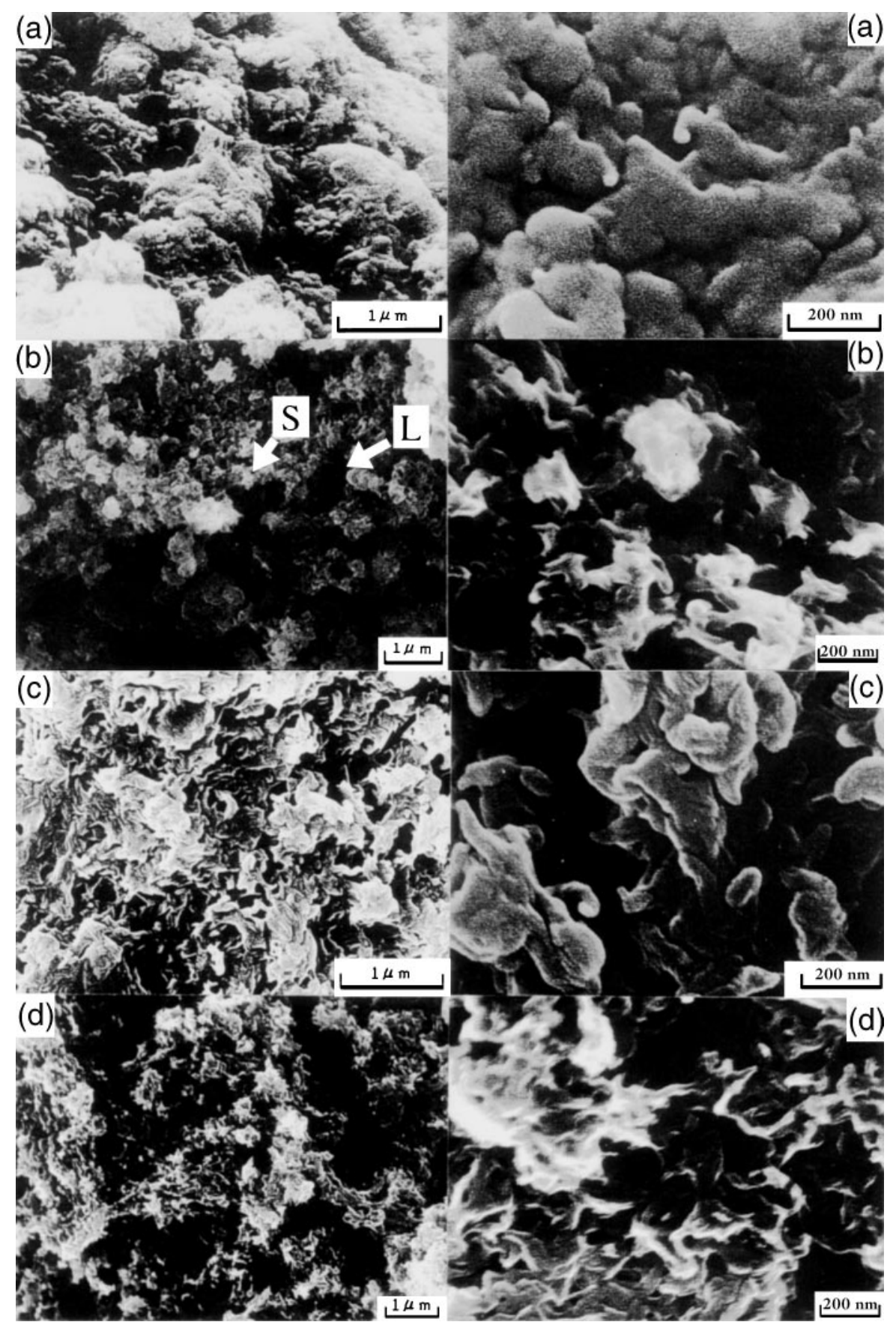

FIG. 5. High resolution FE-SEM pictures of the original PPP sample (a) and the heat-treated PPP-700 (b), PPP-2400 (c), and PPP-2900 (d) powder samples. Low- and high-resolution micrographs are shown on the left and right, respectively, for each sample.

Figure 6 shows the high resolution TEM images of PPP-700 and PPP-2900, for samples similar to those shown in Fig. 5, and in both cases, the samples were not pulverized. The granular samples were directly mounted on the carbon TEM microgrid, and the periphery of the particles was observed in the TEM images, so that the original pore and bulk structures could be observed directly. The periphery of the particles was sufficiently thin for electron beam penetration by electrons accelerated by $400 \mathrm{kV}$ in the TEM instrument. In Fig. 6, short (002) carbon fringes are seen to be randomly arranged in a ribbon-like fashion for PPP2900, with small regions showing several parallel layer stackings. These structures for PPP-2900 tend to give an interlayer spacing that is graphitic, but the entanglement seen in the TEM image (Fig. 7) inhibits an increase in $L_{c}$ to sizes typical of nongraphitizing carbons. 


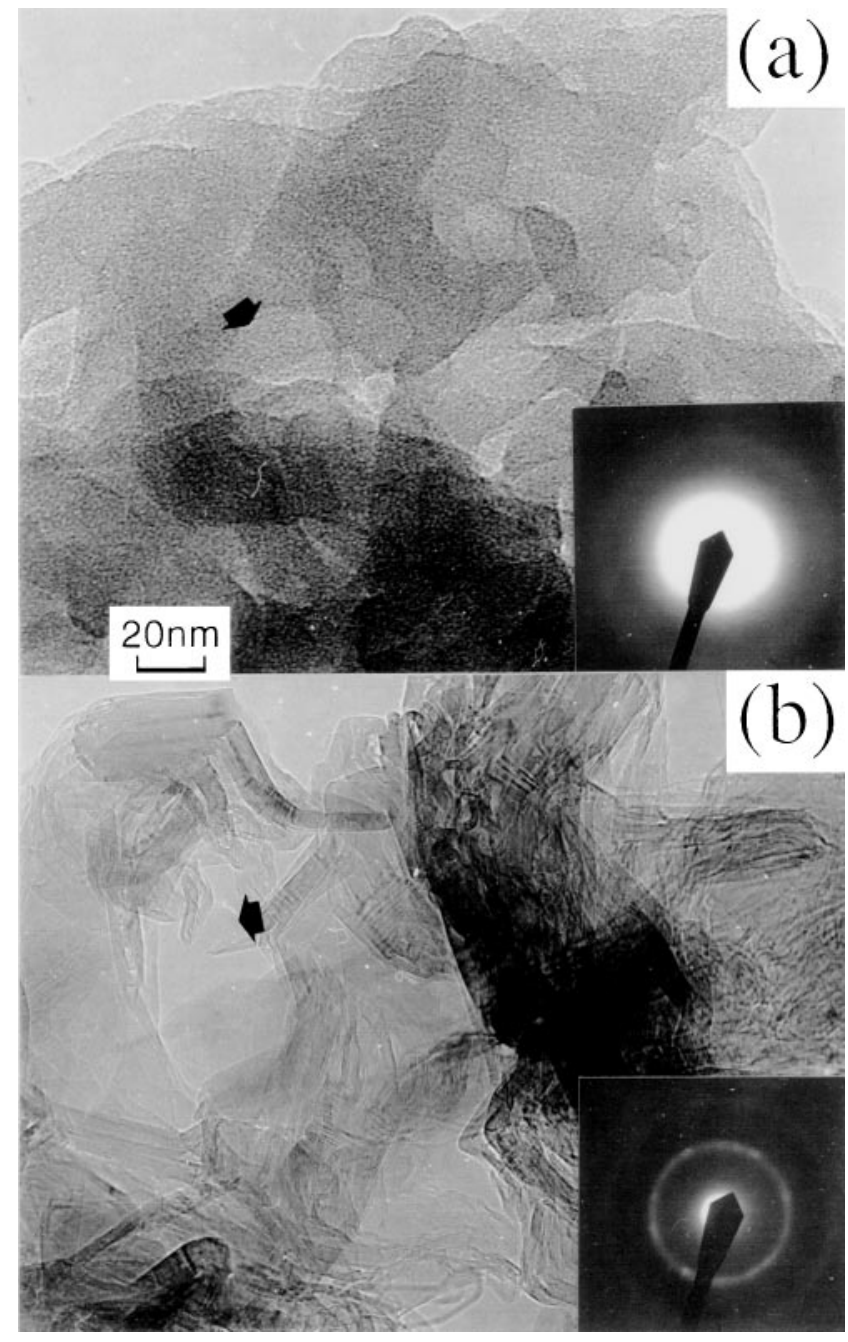

FIG. 6. High resolution, bright-field TEM pictures of PPP-700 (a) and PPP-2900 (b). Insets: Selected area diffraction pattern taken from corresponding images.

The porous structure and amorphous texture are clearly seen in both the bright-field images [see Fig. 6(a)] and the inserted selected area electron diffraction (SAD) pattern for the PPP-700 sample. Oblique pores, as small as $20 \mathrm{~nm}$ in length, are clearly seen (arrow) in the particles, and these small pores may have their origin from the PPP precursor structure. By graphitization at $2900{ }^{\circ} \mathrm{C}$, the PPP-based carbon structure changes to a fibril structure, shown in Fig. 6(b), which remains highly porous, but has a texture intermediate between that of a typical graphitizing and a nongraphitizing carbon, heattreated at the same temperature. ${ }^{12}$ The inserted SAD pattern in Fig. 6(b) shows 002, 10, 004, and 11 rings, but no 112 three-dimensional diffraction line is observed. This indicates that the crystallites are still turbostratic, and consist of small crystallite segments, as shown by x-ray diffraction measurements (see Sec. IV. A).

Figure 7 shows the lattice images corresponding to the bright-field images of Fig. 6 . The very disordered

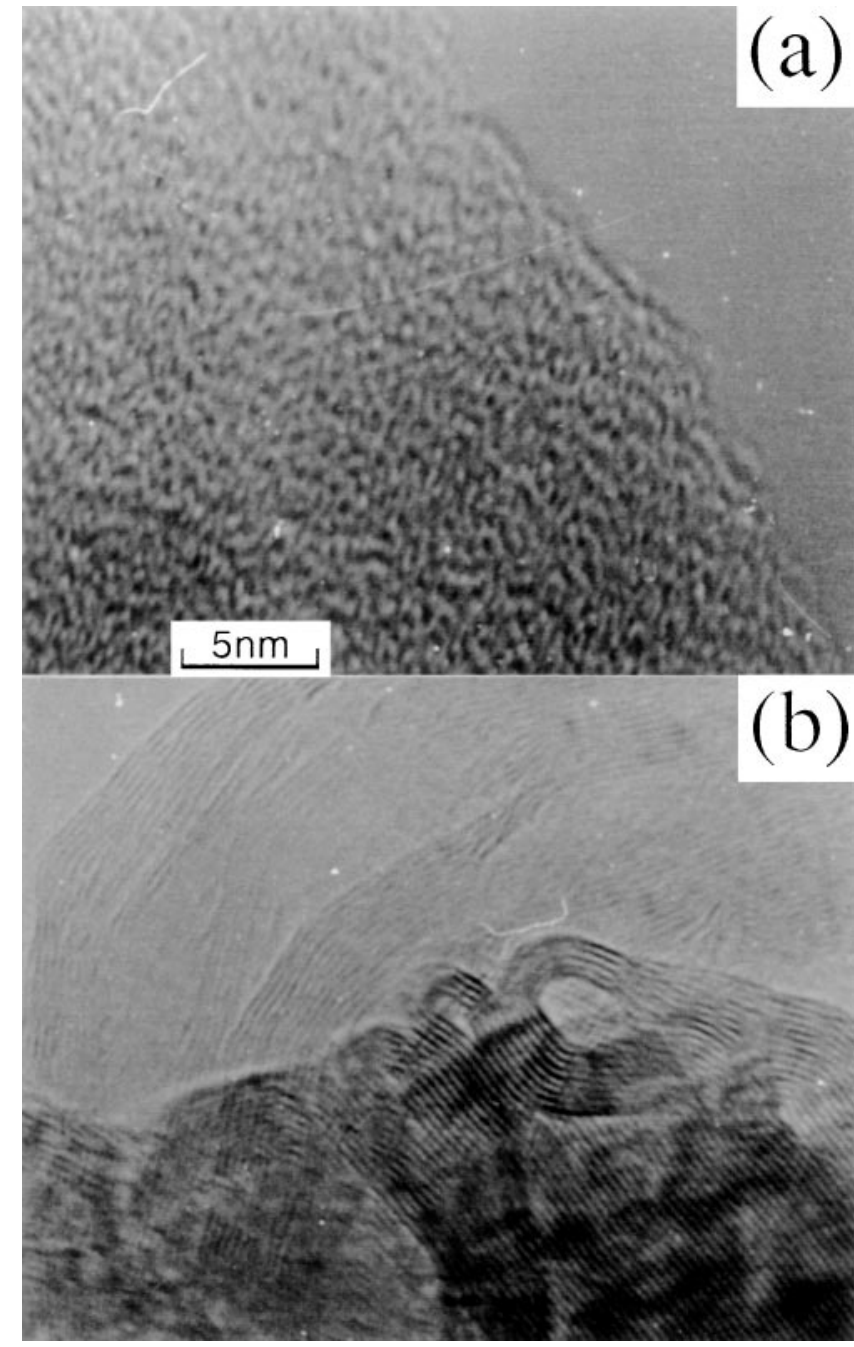

FIG. 7. Lattice images corresponding to the bright-field images in Fig. 6 for PPP-700 (a) and PPP-2900 (b).

lattice images of PPP-700 in Fig. 7(a) change to rather long but poorly aligned fringes upon heat treatment to $2900{ }^{\circ} \mathrm{C}$ in Fig. 7(b), indicative of a fibril structure containing defective (002) layers in the PPP-2900 sample. The carbon interlayer spacing in the PPP-700 sample is found to be $\approx 4 \AA$, while the (002) stacking distance in the PPP-2900 sample is $\approx 3.4 \AA$. The wider interlayer spacing in PPP-700 thus changes to approximately that of graphite by heat treatment to $2900{ }^{\circ} \mathrm{C}$. These structural characteristics of PPP-2900 support the relatively low Li storage capacity reported for PPP-2900, similar to that for less-ordered crystalline graphite. ${ }^{13}$

\section{Raman spectroscopy}

Figure 8 shows Raman spectra taken for samples heat-treated over the broad range $700{ }^{\circ} \mathrm{C} \leqslant T_{\mathrm{HT}} \leqslant$ $2700{ }^{\circ} \mathrm{C}$. Additional spectra were taken for samples heat-treated to $2400{ }^{\circ} \mathrm{C}$ and $2900{ }^{\circ} \mathrm{C}$, so as to compare 


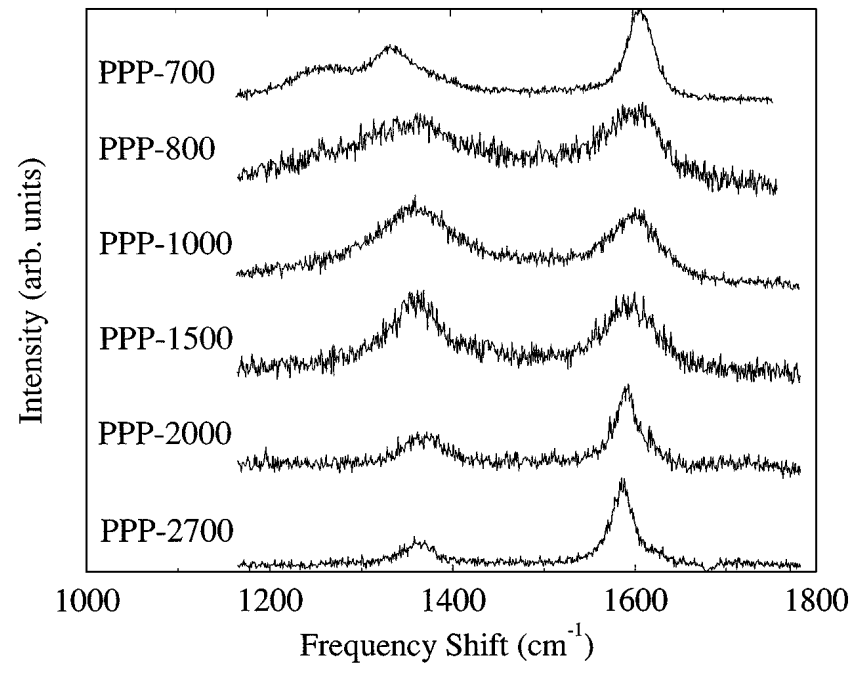

FIG. 8. Raman spectra for several heat-treated PPP samples. The PPP-700 sample exhibits an interesting 3-peak structure due to PPP mode remnants, whereas at higher $T_{\mathrm{HT}}$ the usual "disorder" and "graphite" peaks are observed.

with the XRD data presented in Sec. IV. A and displayed in Table I. Except for PPP-700, each spectrum exhibits two distinct features, one near $1600 \mathrm{~cm}^{-1}$ and the other around $1350 \mathrm{~cm}^{-1}$. An additional third feature around $1260 \mathrm{~cm}^{-1}$ is observed for PPP-700, but this feature seems to be quenched through heat treatment at higher temperatures. For $T_{\mathrm{HT}}>1000^{\circ} \mathrm{C}$, we may identify these two features in the Raman spectra as the familiar Raman-allowed $E_{2 g_{2}}$ mode of graphite $\left(\sim 1580 \mathrm{~cm}^{-1}\right)$ and a disorder-induced mode arising from a breakdown in the $k$-selection rules for graphite $\left(\sim 1360 \mathrm{~cm}^{-1}\right)$. We see that the $E_{2 g_{2}}$ peak for lower $T_{\mathrm{HT}}$ is slightly upshifted, with respect to pure graphite, due to the scattering by disorder-induced non-zone center modes of slightly higher frequency (and probably some residual PPP $A_{g}$ modes as well), but the peak frequency decreases with increasing $T_{\mathrm{HT}}$ to a value of $1585 \mathrm{~cm}^{-1}$ at $2700{ }^{\circ} \mathrm{C}$, nearly equal to the HOPG (highly oriented pyrolytic graphite) value of $1582 \mathrm{~cm}^{-1}$. Correspondingly, as the amount of graphitic order is increased through heat treatment, the intensity of the graphite $E_{2 g_{2}}$ peak $\left(I_{G}\right)$ increases and the intensity of the disorder-induced peak $\left(I_{D}\right)$ decreases. ${ }^{14}$ The ratio of these two peaks can be used as a measure of the degree of order within the $2 \mathrm{D}$ graphene sheets, whereas the $a$-axis microcrystallite size is proportional to the ratio $I_{G} / I_{D}$. We note further that the "disorder" peak frequency also shifts as a function of heat-treatment temperature from roughly $1340 \mathrm{~cm}^{-1}$ for PPP-700 to $1360 \mathrm{~cm}^{-1}$ for PPP-2900. This is most likely due to a quenching of PPP-derived peaks near $1330 \mathrm{~cm}^{-1}$ as $T_{\mathrm{HT}}$ is increased, as discussed below.

It has been found that, for various graphitic carbons such as coke, glassy carbons and HOPG, a simple relation between $L_{a}$ and the $I_{G} / I_{D}$ ratio is observed, yielding the empirical formula ${ }^{15}$

$$
L_{a}=44 \AA \frac{I_{G}}{I_{D}} .
$$

Table I lists the values of $L_{a}$ found through this relation for samples heat-treated above $800{ }^{\circ} \mathrm{C}$. For $T_{\mathrm{HT}}$ below $1000{ }^{\circ} \mathrm{C} L_{a}$ is on the order of $20-30 \AA$, but reaches a maximum value of $120 \AA$ for $T_{\mathrm{HT}}$ near $3000{ }^{\circ} \mathrm{C}$. It should be stressed that this relation holds approximately for a variety of carbons. However, such a relation has been shown to yield an underestimate in $L_{a}$ for the case of nuclear-grade graphite. ${ }^{16}$ This analysis was not applied to PPP-700, since the peaks observed in the Raman spectrum for this sample are influenced by the characteristics of the precursor more than by those of a typical graphitic material. In fact, a more careful study reveals that much of the peak intensities observed for PPP-700 arises from several $A_{g}$ modes of a highly disordered PPP molecular crystal.

In order to study these modes more carefully in the $T_{\mathrm{HT}}$ regime about $700{ }^{\circ} \mathrm{C}$, Raman spectra were taken for samples heat-treated from $650{ }^{\circ} \mathrm{C}$ to $750{ }^{\circ} \mathrm{C}$ in increments of $\Delta T_{\mathrm{HT}}=25^{\circ} \mathrm{C}$. Figure 9 displays the results of these scans, revealing a detailed peak profile which quickly evolves over the given temperature range. Scans on lower $T_{\mathrm{HT}}$ samples proved difficult since a strong luminescence background obscured the Raman peaks. This luminescence effect has been observed in non-heat-treated Kovacic PPP, as well as in other pure polymer samples, and tends to prevent the use of laser excitations in the visible for Raman spectroscopy. ${ }^{17,18}$

The Raman spectrum of pristine PPP has been studied extensively. ${ }^{17,19-21}$ The PPP molecule in its ground state possesses $D_{2 h}$ symmetry, yielding the following

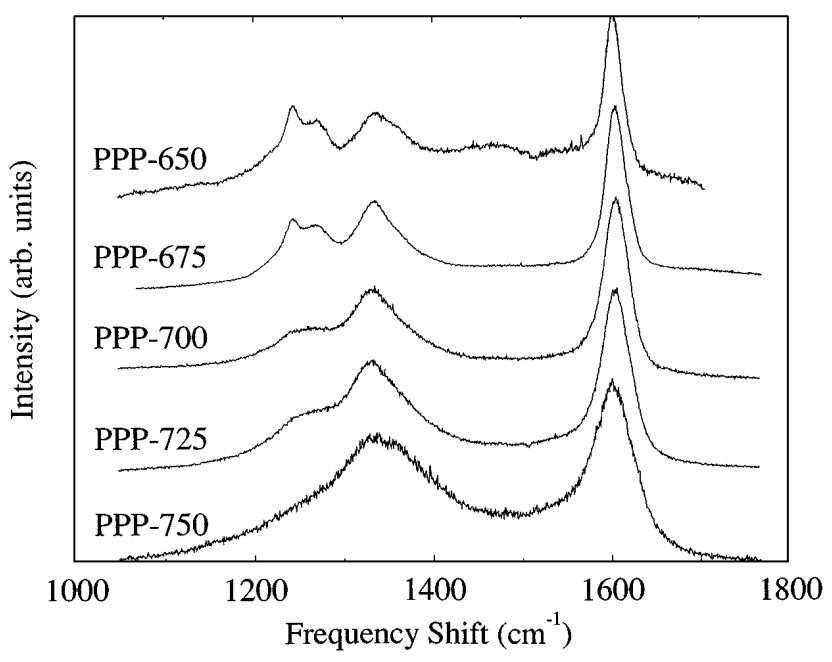

FIG. 9. Raman spectra for PPP heat-treated to temperatures between $650^{\circ} \mathrm{C}$ and $750{ }^{\circ} \mathrm{C}$ showing several PPP-derived $A_{g}$ modes. 
in-plane modes at $k=0$ :

$$
5 A_{g}+5 B_{1 g}+4 B_{2 u}+4 B_{3 u} .
$$

Of these, $3 A_{g}$ modes produce strong Raman lines in the range $1100 \mathrm{~cm}^{-1}$ to $1800 \mathrm{~cm}^{-1}$, namely at $\sim 1220 \mathrm{~cm}^{-1}, \sim 1280 \mathrm{~cm}^{-1}$, and $\sim 1600 \mathrm{~cm}^{-1}$. In our Raman spectrum for PPP-650 and PPP-675, however, we find a relatively sharp peak centered at $1242 \mathrm{~cm}^{-1}$, a broad peak centered at around $1270 \mathrm{~cm}^{-1}$, and a broad, but strong, peak centered at $1334 \mathrm{~cm}^{-1}$, along with the relatively unchanged $1600 \mathrm{~cm}^{-1}$ peak. Upon careful decomposition of Lorentzian lineshapes through a least-squares fitting procedure, two other peaks near $1218 \mathrm{~cm}^{-1}$ and $1360 \mathrm{~cm}^{-1}$ could be accounted for, thereby producing the best fit. Although the benzenoid (nondegenerate) ground state of PPP produces lines around $1220 \mathrm{~cm}^{-1}$ and $1280 \mathrm{~cm}^{-1}$, it is well known that a (higher energy) quinoid state exists for the molecule, producing Raman lines near $1240 \mathrm{~cm}^{-1}$ and $1330 \mathrm{~cm}^{-1}$, slightly higher in frequency from those for the benzenoid system due to a redistribution of $\mathrm{C}-\mathrm{C}$ double-bonds. The $\mathrm{C}-\mathrm{C}$ stretch mode producing the peak near $1600 \mathrm{~cm}^{-1}$ remains unshifted as a result of heat treatment in this $T_{\mathrm{HT}}$ range. Thus, the lines at $1240 \mathrm{~cm}^{-1}$ and $1330 \mathrm{~cm}^{-1}$ could imply the presence of regions in the sample with a quinoid-like structure produced by the introduction of defect states through heat treatment. Although the ideal quinoid structure, which is a planar structure due to the double-bond bridging of phenyl groups, has a higher overall energy per PPP chain than the ideal benzenoid structure, strong correlation between exposed orthosites of neighboring PPP chains in the defective PPP material may act to lower the energy of the quinoid state per group of neighboring PPP chains. Ultimately, a planar configuration of phenyl groups is energetically favored as the heat-treated solid loses more hydrogen and eventually forms small graphene sheets. The lines near 1218 and $1270 \mathrm{~cm}^{-1}$, then, could be due to benzenoid PPP peak remnants, which appear slightly downshifted.

It should be noted that, at these low heat-treatment temperatures $\left(T_{\mathrm{HT}} \leqslant 700^{\circ} \mathrm{C}\right)$, the PPP samples have lost much (though not all) of their hydrogen, and many molecular defects due to hydrogen vacancies will be present. Indeed, previous work on PPP thin films indicates that at temperatures near $675^{\circ} \mathrm{C}$ (for $1 \mathrm{~h}$ residence time), $\mathrm{H}_{2}$ and $\mathrm{CH}_{4}$ gases begin to evolve from the polymer. $^{22}$ Therefore, an interpretation of the Raman spectra for low $T_{\mathrm{HT}}$ samples in terms of a disordered PPP, rather than a disordered graphitic carbon, seems reasonable. It is interesting to note that the Raman peak near $1600 \mathrm{~cm}^{-1}$ is relatively robust through the range $650{ }^{\circ} \mathrm{C} \leqslant T_{\mathrm{HT}} \leqslant 725^{\circ} \mathrm{C}$, indicating that most of the carbon ring systems do not become dismantled through heat treatment. Hence, the high frequency $\mathrm{C}-\mathrm{C}$ stretch mode within each ring persists despite drastic structural changes resulting from heat treatment. The stretch mode associated with the $\mathrm{C}-\mathrm{C}$ nearest neighbors eventually becomes an $E_{2 g_{2}}$ graphite mode under $D_{6 h}^{4}$ space group symmetry for $T_{\mathrm{HT}}>800{ }^{\circ} \mathrm{C}$. The special properties of PPP-700 can be attributed to the presence of both a PPP-like short-range structure and an immaturely formed disordered graphene arrangement. Raman analysis suggests that, at a $T_{\mathrm{HT}}$ of $700{ }^{\circ} \mathrm{C}$, the PPP samples are only partially carbonized and show the signature of a highly disordered quinoid-like PPP structure.

\section{Electrical properties}

Figure 10 shows the effect of heat treatment on the room temperature resistivity of small PPP sample bars. The resistivity results in Fig. 10 show three clear regions of behavior, as is also observed in typical graphitizing carbons. At low $T_{\mathrm{HT}}$ values $\left(700-1000{ }^{\circ} \mathrm{C}\right)$, the resistivity drops by many orders of magnitude, from $\rho \sim 3.6 \times 10^{1} \Omega$-cm at $T_{\mathrm{HT}} \sim 600{ }^{\circ} \mathrm{C}$ to $3.0 \times$ $10^{-2} \Omega-\mathrm{cm}$ at $1000{ }^{\circ} \mathrm{C}$. This drop in $\rho$ is identified with the formation of a $\pi$-band from the insulating molecular coordination of PPP $\left(E_{g} \sim 3.4 \mathrm{eV}\right)$. The second region $\left(1000{ }^{\circ} \mathrm{C}<T_{\mathrm{HT}}<2000{ }^{\circ} \mathrm{C}\right)$ shows almost no change in $\rho$, corresponding to a competition effect between the decrease in dangling bond concentration (see Sec. IV.E.) and a decrease in carrier localization

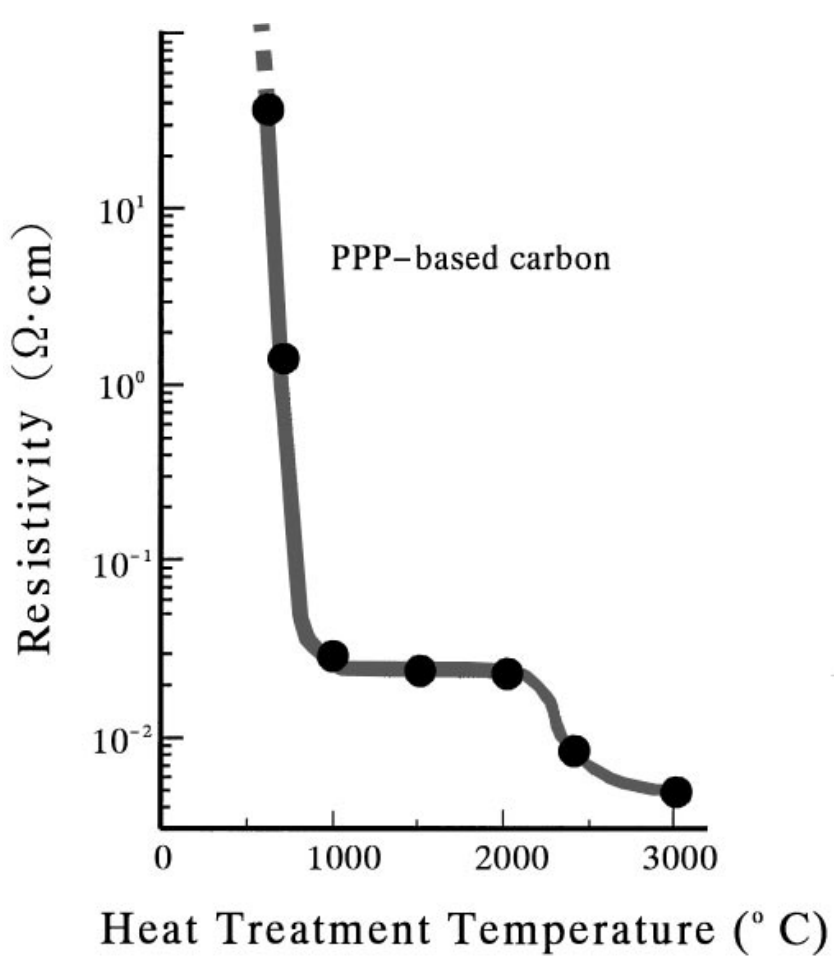

FIG. 10. Room temperature resistivity versus heat-treatment temperature showing typical soft carbon behavior for PPP-derived carbon. The plateau corresponds to a competition between decreasing carrier density and increasing carrier mobility due to a decrease in carrier scattering. 
and the increased mobility through the development of $L_{a}$, the in-plane crystallite size. Above $2000{ }^{\circ} \mathrm{C}$, the graphene band structure starts first to develop as $2 \mathrm{D}$ ordering and at the highest $T_{\mathrm{HT}}$ value near $3000{ }^{\circ} \mathrm{C}$, some 3D interplanar correlation sets in. These structural changes begin to influence carrier conduction, producing a resistivity of $5.0 \times 10^{-3} \Omega$-cm for PPP-3000. These three temperature regions are closely correlated with the dependence of $d_{002}$ on $T_{\mathrm{HT}}$ described in Fig. 4. However, the lowest resistivity obtained for the PPP3000 sample is $\sim 2$ orders of magnitude higher than for conventional graphite materials. This high $\rho$ value is explained by the small crystallite size of the PPP-based carbon, even after graphitization. This is consistent with the dual graphitizing and nongraphitizing aspects of the PPP-based carbon. Graphitic aspects are found in terms of demonstrating the three regions of resistivity behavior shown in Fig. 10. In contrast, nongraphitizing carbons show only two regions in $\rho(T)$ as a function of $T_{\mathrm{HT}}$. The relatively high value of $\rho$ at $300 \mathrm{~K}$ for PPP-based carbon, however, indicates the presence of nongraphitic behavior, which we attribute to short $L_{a}$ and $L_{c}$ values.

Figure 11 shows the temperature dependent $\rho(T)$ for various $T_{\mathrm{HT}}$ samples. The $\rho(T)$ curves for PPP-700 and PPP-800 show a clear "semiconducting" $T$ dependence, typical of disordered carbons. But as $T_{\mathrm{HT}}$ increases, $\rho(T)$ shows approximately $T$-independent behavior, and somewhat lower values of the room temperature resistivity, characteristic of the intermediate region of $T_{\mathrm{HT}}$ behavior

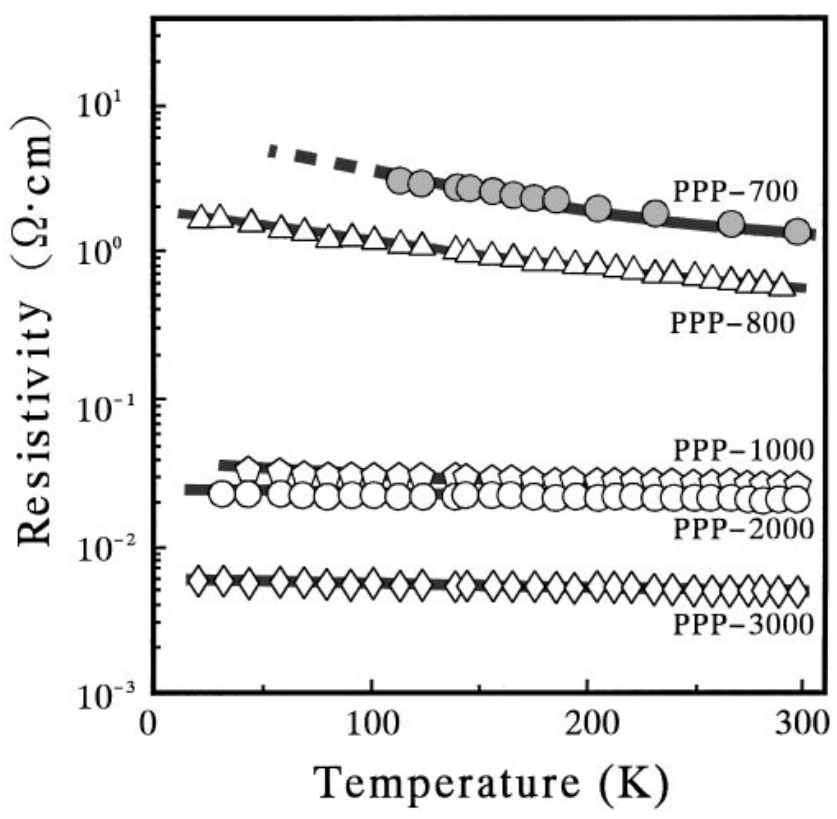

FIG. 11. $\rho(T)$ for PPP samples heat-treated to various $T_{\mathrm{HT}}$ values. The flatness of the curves and the absence of a "metallic" temperature dependence for $\rho(T)$ at high heat-treatment temperatures is associated with small $L_{c}$ values. in Fig. 10. In this regime $\rho(T)$ varies very weakly with $T_{\mathrm{HT}}$. However, as the high $T_{\mathrm{HT}}$ regime is reached, the room temperature $\rho$ value again starts to decrease, while $\rho(T)$ remains flat. As shown in Fig. 11, the $\rho(T)$ for $T_{\mathrm{HT}} \sim 3000{ }^{\circ} \mathrm{C}$ shows no metallic temperature behavior at low temperature, consistent with the small $L_{c}$ value of the PPP-3000 and corresponding high density of scattering centers.

\section{E. Magnetic susceptibility}

Temperature-dependent susceptibility measurements (Fig. 12) for samples heat-treated in the range $650{ }^{\circ} \mathrm{C} \leqslant$ $T_{\mathrm{HT}} \leqslant 2700{ }^{\circ} \mathrm{C}$ are well fit by a Curie law $\chi=$ $(C / T)+\chi_{0}$ over the measurement temperature range $4<T<20 \mathrm{~K}$ where the constant offset, $\chi_{0}$, represents the temperature-independent diamagnetic contribution. From the slope of $\chi$ vs $1 / T$, the Curie constant

$$
C=\frac{N_{\mathrm{loc}} S(S+1) g^{2} \mu_{B}^{2}}{3 k_{B}}
$$

is obtained, from which we extract the localized spin concentration $\left(N_{\text {loc }}\right)$ for each PPP sample (Fig. 13). We see that the number of unpaired localized spins increases with increasing $T_{\mathrm{HT}}$ at low heat-treatment temperatures, reaches a maximum between $750{ }^{\circ} \mathrm{C}$ and $800{ }^{\circ} \mathrm{C}$, and gradually decreases upon heat treatment to higher temperature. For $T_{\mathrm{HT}}>800^{\circ} \mathrm{C}$, we can tentatively correlate $N_{\text {loc }}$ with the relative integrated intensity of the disorder peak from Raman data, $\left(I_{D} / I_{G}\right)^{-1}$. Thus, as graphitization proceeds at higher $T_{\mathrm{HT}}$ values, the number of unpaired spins per unit volume formed at the dangling bonds along the edges of the pregraphitic microcrystallites tends to decrease as the amount of "edge" versus "volume" of a given microcrystallite decreases.

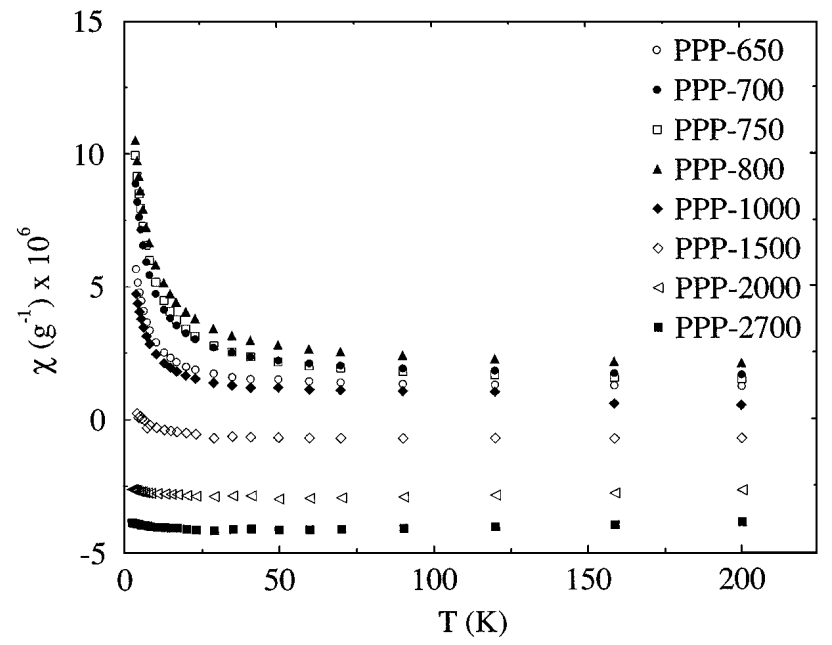

FIG. 12. Temperature dependent magnetic susceptibility measurements for PPP samples heat-treated to various $T_{\mathrm{HT}}$ values. 


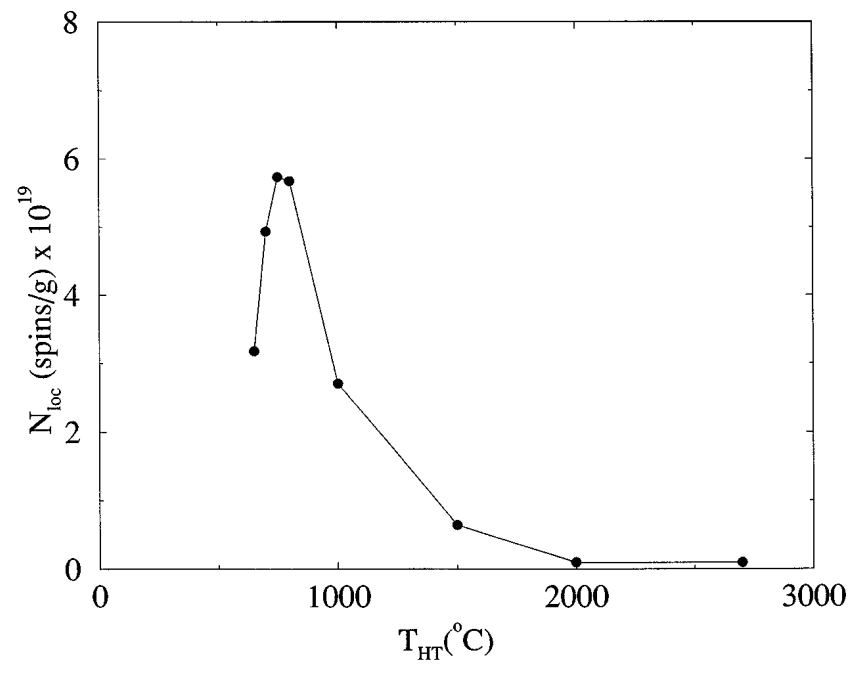

FIG. 13. Localized spin density $\left(N_{\text {loc }}\right)$ as a function of $T_{\mathrm{HT}}$.

As indicated earlier, analysis of samples heat-treated in the range $650{ }^{\circ} \mathrm{C} \leqslant T_{\mathrm{HT}} \leqslant 800^{\circ} \mathrm{C}$ is best done from the perspective of a disordered $\left(T_{\mathrm{HT}}<775^{\circ} \mathrm{C}\right)$ polymer, as opposed to a disordered carbon $\left(T_{\mathrm{HT}}>775^{\circ} \mathrm{C}\right)$. Hence, disorder decreases as we move away from the peak near $T_{\mathrm{HT}} \sim 775^{\circ} \mathrm{C}$ in Fig. 13 , for either increasing or decreasing $T_{\mathrm{HT}}$. At a $T_{\mathrm{HT}}$ of $650{ }^{\circ} \mathrm{C}$, many edge sites of the carbonaceous clusters, consisting of partially dehydrogenated PPP, are terminated by hydrogen atoms. These hydrogen atoms are quickly expelled at higher $T_{\mathrm{HT}}$, thus exposing unpaired electrons localized at carbon atoms along the edges and within the bulk of the crystallites. For sample PPP-700, the exposure of hydrogen-terminated sites is only partially complete, implying that each crystallite will have many dangling bonds as well as hydrogen atoms at edge locations. Interestingly, very near $T_{\mathrm{HT}}=700^{\circ} \mathrm{C}$ we find a global maximum in the total number of unpaired spins in our system. This peak bears a striking resemblance to the peak in evolved $\mathrm{H}_{2}$ as a function of $T_{\mathrm{HT}}$ reported in Ref. 22 for measurements done on thin film PPP. Thus, the special properties of PPP-700 may be related to this maximal exposure of ortho-sites which produces a maximum of localized spins.

\section{DISCUSSION}

In the present work, PPP-based carbons were characterized in terms of structural, lattice, and electronic properties in an attempt to better understand these materials, particularly those heat-treated in the $675^{\circ} \mathrm{C}<$ $T_{\mathrm{HT}}<775^{\circ} \mathrm{C}$ temperature range, where the most dramatic changes in physical properties occur due to the carbonization of the polymer precursor. In this low- $T_{\mathrm{HT}}$ regime, XRD measurements reveal short range (3.77 Å) $d_{002}$-spacing consistent with literature values for highly disordered carbon structures. Raman studies reveal that, for PPP samples with $T_{\mathrm{HT}} \sim 700{ }^{\circ} \mathrm{C}$, features in the Raman spectrum between $1200 \mathrm{~cm}^{-1}$ and $1400 \mathrm{~cm}^{-1}$ may be identified with modes derived from each of the resonant PPP molecular structures. Thus, at low $T_{\mathrm{HT}}$, Raman and XRD results suggest the coexistence of a mostly quinoid-like disordered PPP material with smaller amounts of benzenoid-PPP and turbostratic graphene constituents. Furthermore, the transport behavior for $T_{\mathrm{HT}}<800{ }^{\circ} \mathrm{C}$ is dominated by strongly localized carriers originating from the large band gap of PPP prior to heat treatment. Although many aromatic ring structures exist for $T_{\mathrm{HT}}<800^{\circ} \mathrm{C}$, mostly in small PPP-like clusters, the high density of dangling bonds and the semiconducting nature of the disordered PPP indicate the absence of a conductive pathway, and therefore of extended $\pi$-bands. This picture drastically changes as $T_{\mathrm{HT}}$ is increased above $800{ }^{\circ} \mathrm{C}$, where carbonization proceeds, the dangling bond concentration drops, and correspondingly the conductivity increases by over 3 orders of magnitude. This increase in pregraphitic carbon conductivity occurs as the PPP character of the samples diminishes, leaving behind a novel form of disordered carbon. Whereas these PPP-based carbons can almost be characterized as a glassy carbon in terms of their limiting $L_{a}$ and $L_{c}$ values at high $T_{\mathrm{HT}}$, the short interplanar distance $(3.37 \AA)$ near $3000^{\circ} \mathrm{C}$ is almost equal to the $d_{002}$ spacings of graphite $(3.35 \AA)$. The tendency for PPP-700 to accommodate large concentrations of $\mathrm{Li}$ is believed to be linked with these coexisting graphitizing/nongraphitizing characteristics in that they both arise from the strong structural influence of the aromatic polymer precursor. In terms of graphitizability, the formation of extended graphene sheets from columnar crystallites in pregraphitic PPP-based carbons is prevented by the presence and entanglement of PPP chains up to relatively high temperatures $\left(\sim 800^{\circ} \mathrm{C}\right)$. This high-temperature stability, in fact, is one of the outstanding characteristics of PPP, enabling it to form an entangling structure at high temperatures. However, since the partially dehydrogenated molecules formed below $800{ }^{\circ} \mathrm{C}$ are expected to be planar due to their quinoid confirmation, adjacent chains are able to pack closely, allowing for close $d_{002}$-spacings at higher $T_{\mathrm{HT}}$. In the low- $T_{\text {HT }}$ regime, PPP-based carbons are thought to consist of a long-range polymeric entanglement, while supporting a local environment of mostly quinoid-PPP chains arranged roughly in coplanar alignments, with smaller amounts of benzenoid-PPP and disordered carbon constituents. The large $d_{002}$-spacings for the disordered carbon regions imply the presence of large open channels, both in the carbonized and precarbonized quinoid-PPP regions, consistent with SEM observations. These large open channels should enhance the mobility of Li dopants, as well as providing accessibility of lithium to various sites. Furthermore, we also expect 
an increase in total available localization sites for $\mathrm{Li}$ in PPP-700, since a highly flexible structure with many edge sites is created through dehydrogenation. Thus, the delicate structure produced at $T_{\mathrm{HT}}=700{ }^{\circ} \mathrm{C}$ can accommodate large amounts of $\mathrm{Li}$ due to a maximum in both vacant and accessible sites.

\section{ACKNOWLEDGMENTS}

The authors are thankful to Dr. G. Dresselhaus for stimulating discussions and to Dr. Don Heiman for the generous use of optical equipment and for useful discussions. The MIT authors gratefully acknowledge support for this work under NSF Grant DMR 95-10093 and LLNL Subcontracts B295139 and B287707.

\section{REFERENCES}

1. M. Mohri, J. Yanagisawa, Y. Tajima, H. Tanaka, T. Mitate, S. Nakajima, M. Yoshida, Y. Yoshimoto, T. Suzuki, and H. Wada, J. Power Sources 26, 545 (1989).

2. I. Kuribayashi, M. Yokoyama, and M. Yamashita, J. Power Sources 54, 1 (1995).

3. R. Yazami and D. Guerard, J. Power Sources 43, 39 (1993).

4. T. Zheng, Y. Liu, E. W. Fuller, S. Tseng, U. von Sacken, and J. R. Dahn, J. Electrochem. Soc. 142, 2581 (1995).

5. K. Tatsumi, N. Iwashita, H. Sakeabe, H. Shioyama, S. Higuchi, A. Mabuchi, and H. Fujimoto, J. Electrochem. Soc. 142, 716 (1995).
6. J. R. Dahn, A. K. Sleigh, H. Shi, B. M. Way, W. J. Weycanz, J. N. Reimers, Q. Zhong, and U. von Sacken, in New Materials and Perspectives (North-Holland, Amsterdam, 1993).

7. K. Sato, M. Noguchi, A. Demachi, N. Oki, and M. Endo, Science 264, 556 (1994).

8. P. Kovacic and A. Kyriakis, J. Am. Chem. Soc. 85, 454 (1963).

9. I. L. Spain, in Chemistry and Physics of Carbon, edited by P.L. Walker, Jr. and P. A. Thrower (Marcel Dekker, New York, 1981), Vol. 16, p. 119.

10. M.S. Dresselhaus, G. Dresselhaus, K. Sugihara, I.L. Spain, and H. A. Goldberg, Graphite Fibers and Filaments (Springer-Verlag, Berlin, 1988), Vol. 5 of Springer Series in Materials Science.

11. Y. Hishiyama, Y. Kaburagi, and M. Inagaki, Mater. Sci. Forum 91-93, 239 (1992).

12. A. Oberlin, in Chemistry and Physics of Carbon, edited by P.A. Thrower (Dekker, New York, 1989), Vol. 22, p. 1.

13. M. Endo, Y. Nishimura, T. Takahashi, K. Takeuchi, and M. S. Dresselhaus, J. Phys. Chem. Solids 57, 725 (1996).

14. F. Tuinstra and J. L. Koenig, J. Chem. Phys. 53, 1126 (1970).

15. D. S. Knight and W. B. White, J. Mater. Res. 4, 385 (1989).

16. L. Nikiel and P. Jagodzinski, Carbon 31, 1313 (1993).

17. S. Krichene, S. Lefrant, G. Froyer, F. Maurice, and Y. Pelous, J. Phys. (Paris) Colloq. 44, C3-733 (1983).

18. S. Krichene, J.P. Buisson, and S. Lefrant, Synth. Met. 17, 589 (1987).

19. Z. Iqbal, H. Bill, and R.H. Baughman, J. Phys. (Paris) Colloq. 44, C3-761 (1983).

20. J. P. Buisson, S. Krichene, and S. Lefrant, Synth. Met. 21, 229 (1987).

21. G. Zannoni and G. Zerbi, J. Chem. Phys. 82, 31 (1985).

22. Y. Yamada, T. Furuta, M. Shiraishi, M-A. Sato, and K. Kaeriyama, J. Mater. Sci. 24, 3113 (1989). 